\title{
CONCEPÇÕES SOBRE ESTRATÉGIAS TRADUTÓRIAS: QUESTÕES LÉXICO- SEMÂNTICAS, MORFOSSINTÁTICAS E INTERCULTURAIS NO POEMA A BALADA DO CÁRCERE DE READING, DE OSCAR WILDE
}

\author{
Maria Elizete Pereira dos ANJOS \\ Universidade Estadual de Goiás \\ Dr. Ariovaldo Lopes PEREIRA \\ Universidade Estadual de Goiás
}

RESUMO: O presente artigo intenta apresentar reflexões acerca de estratégias utilizadas por estudantes no processo de tradução interlingual de textos para português. Para tanto foi realizada uma análise de atividade de tradução envolvendo professores de língua inglesa em formação do terceiro ano do curso licenciatura em Letras da Universidade Estadual de Goiás (UEG), Câmpus Posse. A atividade girou em torno da tradução-compreensão de um fragmento do poema do autor irlandês Oscar Wilde, intitulado Balada do Cárcere de Reading, que compõe o livro Profundis, escrito na ocasião em que o autor esteve preso sob acusação de ferir a moral e a ética social por meio de práticas homossexuais. O resultado das observações foi apresentado em forma de texto descritivo e revela as nuanças por que passam os vocábulos no momento da tradução, demonstrando que os estudantes geralmente iniciam o processo tradutório apoiando-se em conhecimentos macrotextuais e posteriormente se baseiam em orientações léxico-semânticas, morfossintáticas e interculturais.

PALAVRAS CHAVE: Tradução; Estratégias tradutórias; Língua inglesa.

ABSTRACT: The goal of this article is to reflect on the strategies used by students translating texts from English languages into Portuguese. To that end a translation activity involving English students in their third year of the Teaching degree course in languages from Goiás State University (UEG), Posse city Campus, was analyzed. The activity revolved around the translation of a fragment of the Oscar Wilde poem "The Ballad of Reading Jail " from the book De Profundis, written when the author was imprisoned accused of insulting morals and ethics by committing homosexual acts. The results of these observations were presented in the form of descriptive texts revealing that vocabulary in translation passes through nuances of meaning, demonstrating that students generally begin the translation process supporting themselves with macro-textual knowledge and later orienting themselves using lexical, morphological, semantic and intercultural points of referencing.

KEY-WORDS: Translation; Translation Strategies; English Language

\section{Introdução}

$\mathrm{O}$ ato tradutório é envolto por crenças de que se resume simplesmente numa ação de transpor vocábulos de uma língua para vocábulos equivalentes em outra língua. Na prática, esse processo mecânico não funciona, pois para além do domínio e conhecimento especialmente da língua de chegada, ou seja, aquela para a qual se está traduzindo, quem traduz deve ter sempre a flexibilidade no momento da transferência linguística, atentando, sobretudo, para possíveis precedentes e invenções de novas soluções que darão sentido ao texto na língua de chegada.

Pesquisas nessa direção tornam-se relevantes, considerando os aspectos polêmicos que envolvem o trabalho pedagógico com tradução interlingual de textos no processo de ensino aprendizagem de língua estrangeira, comumente vista como atividade mecânica e desprovida de sentido para os aprendizes.

Entendemos ainda que quem está a traduzindo mesmo que de forma inconsciente e irrefletida, utiliza estratégias que permitem percorrer caminhos que colaborem para que o 
texto de chegada possa alcançar bons níveis de adequação, sem incorrer em desvios e enganos linguísticos.

Foi à luz de tais constatações, reflexões e indagações que propusemos acompanhar por meio de observação uma atividade de tradução interlingual envolvendo professores de língua inglesa em formação do terceiro ano do curso licenciatura em Letras da Universidade Estadual de Goiás (UEG), Câmpus Posse, com a intenção de analisar as estratégias que os referidos estudantes utilizam no processo de tradução interlingual de textos e, com isso, compreender que aspectos são mais recorrentes nesse processo.

Para empreender o objetivo proposto, a saber, apresentar reflexões acerca de estratégias utilizadas por estudantes no processo de tradução de textos, propusemos analisar uma atividade de tradução de um fragmento do poema do autor irlandês Oscar Wilde, intitulado Balada do Cárcere de Reading, que compõe o livro Profundis.

O poema de Oscar Wilde foi escolhido para este estudo por se tratar um texto formado por frases absolutas ou por períodos compostos, em sua maioria por orações coordenadas, o que facilitaria o trabalho tradutório a ser desenvolvido pelos estudantes.

Para apresentar o resultado da análise das estratégias utilizadas pelos estudantes, foram selecionadas algumas palavras e expressões do poema que evidenciaram as estratégias adotas por estes, para realizar a tradução-compreensão do texto.

Esperamos que os resultados das observações possam colaborar para reflexões que culminem em novas práticas envolvendo professores de língua inglesa em formação no que tange ao trabalho com tradução interlingual em sala de aula.

\section{Tradução: Questões de letra, espirito e interculturalidade}

No contexto de democratização de viagens, de amplo acesso às tecnologias de comunicação e informação, o que nos permite ampliar os horizontes culturais por meio do contato com diversas línguas, a tradução tem seu papel expandido, ampliado e diversificado, seja no âmbito do especialista, do leigo ou em contextos das práticas pedagógicas de ensino de língua estrangeira.

Ademais, vale ressaltar a relevância que a tradução ostenta na aprendizagem de línguas estrangeiras, sobretudo no que se refere ao conhecimento e reflexão sobre a língua materna por meio da comparação e do contraste, pois quem não conhece línguas estrangeiras não sabe nada da sua própria, asseverou o grande tradutor Goethe. $\mathrm{O}$ que pode ser visto e compreendido de forma inversa, a partir do entendimento de que o conhecimento que temos da própria língua contém, em potência, o conhecimento de todas as outras - por intermédio da tradução (OUSTINOFF,1956, p. 10).

A tradução, do grego, traductio, pode significar passar de um estado para o outro. Dessa forma, promove uma condição de interação, podendo, no entendimento de Gorovitz (2001), ser compreendida como situação de passagem entre culturas e realidades, entre línguas, autores, obras e leitores.

De acordo com Campos (1986), a tradução não se limita apenas a uma simples transposição de uma língua para a outra, mas envolve a bagagem cultural de ambas as línguas, ou seja, o tradutor traduz de uma cultura para a outra.

$\mathrm{O}$ ato de traduzir já foi relacionado puramente à letra (tradução literal, pura) como o fez Chateaubriand, ao traduzir Paraíso Perdido, de Jonh Milton, em 1836, que em suas observações demonstra resignação em efetuar uma tradução "elegante", acrescentando imediatamente: "é uma tradução literal na mais forte acepção do termo a que eu empreendi, 
uma tradução cujo texto uma criança ou um poeta poderão seguir, a linha, palavra a palavra, como um dicionário aberto diante dos nossos olhos" (Chateaubriand,1789, apud OUSTINOFF, 1956, p.48).

Em que pese o fato de o ato tradutório já ter sido concebido apenas no aspecto da letra, entendemos que tal processo não pode ser restringido apenas à dimensão linguística, pois se assim o fosse, para uma boa tradução seria necessário apenas um bom linguista que tivesse amplo domínio da língua estrangeira e da língua-alvo. A compreensão e o domínio do léxico da língua de partida configura-se em uma condição importante, mas não satisfatória, pois para além do domínio linguístico, acrescenta-se à tarefa do tradutor, fazer com que vida interior espírito da expressão traduzida corresponda à vida interior do seu original.

Ademais, ao traduzir não podemos considerar a língua como um simples instrumento, como uma operação intransitiva que acontece entre o pensamento e sua expressão, pois não podemos conceber a existência de traduções imparciais ou diáfanas, através da qual o texto original surgiria "idealmente como um espelho, identicamente" (OUSTINOFF,1956, p. 22).

Com isso, à função comunicativa da tradução, juntamente com a função linguística, deve ser adicionada a função intercultural a partir do entendimento de que o ato de traduzir um texto não pode ser reduzido apenas à busca de equivalentes linguísticos, à transferência irrefletida de itens lexicais e de estruturação morfossintática, mas trata-se de um processo de passagem, de comparação entre as duas línguas, sugerindo a consideração do contexto e dos cenários em que os dois textos foram produzidos.

Isso significa dizer que o ato tradutório pode estar relacionado ao espírito (ao considerar o entendimento, os valores, as crenças e a cultura dos usuários do texto de chegada), como o fez Lutero (1512) ao traduzir a Bíblia para a língua alemã.

Não é às palavras da língua materna que devemos perguntar como se deve falar alemão, como fazem esses asnos; mas à mãe em seu lar, às crianças nas ruas, ao homem do povo na praça do mercado que é preciso perguntar, lendo em seus lábios como eles falam, e depois disso que se deve traduzir, porque assim eles compreenderão e se darão conta de que lhes estamos falando em alemão. (Lutero,1512, apud OUSTINOFf, 1956, p. 17).

Existe uma clara concepção, embora unilateral e por isso duvidosa, segundo a qual, para melhor se compreender e apreender a cultura do outro faz-se necessário mover-se para ela e, "depois de ter esquecido a sua, olhar para o mundo com os olhos da cultura do outro" (BAKHTIN, 2003, p.365).

Mesmo ao considerar a cultura dos usuários do texto de chegada, na época em que foram traduzidos os textos sagrados para o alemão, ninguém se aventuraria modificar a palavra divina, sob pena de ser levado diretamente à fogueira, como aconteceu com Étienne Dolet, enforcado e queimado em 1546 em Paris.

Lutero entendia que a "letra mata, mas o espírito vivifica" (2 CORÍNTIOS 3,6) na mesma medida que entendia que era preciso ser fiel à mensagem transmitida nos textos sagrados, para recriar o espírito do original. Com isso seria necessária uma traduçãointerpretação que não renunciasse a si mesma, que não afastasse o intérprete no tempo, nem no espaço, nem na cultura em relação àquilo que se pretendia reinterpretar de forma criativa. Com efeito, "nesse encontro dialógico de duas culturas elas não se fundem nem se confundem; cada uma mantém sua unidade e sua integridade aberta, mas se enriquecem mutuamente". (BAKHTIN, 2003, p.365). 
Isso denota que uma boa tradução deve considerar questões léxico- semânticas, de estruturações morfossintáticas mas, sobretudo, o diálogo intercultural no momento de passagem entre as duas línguas por meio de valores que as pessoas transportam. Vista sob esse ângulo,

a tradução é um diálogo de individualidades criadoras de diferentes culturas, isto é, um autêntico diálogo de culturas, no qual o tradutor escarafuncha as entranhas do original, ausculta as vozes que o povoam, entranha-se às vezes no quase insondável da linguagem, compenetra-se da vida de suas personagens; em suma, embebe-se do original para poder interpretá-lo em seu conjunto e dar-lhe uma nova vida, vida essa, porém, marcada pela singularidade dos múltiplos modos de ser da língua e da cultura do tradutor, por sua individualidade criadora. (BEZERRA, 2012, p.2)

Assim, ao traduzir um texto é preciso fazer interpretação, análise e comparação entre a cultura do texto de chegada e a do texto de partida, fazendo com que o texto traduzido reflita as diferenças e semelhanças socioculturais impregnadas na língua, que vai além da transposição linguística.

Sobre isso, concordamos com Katan (2004), quando advoga em favor da conscientização do papel desempenhado pela cultura no processo de tradução: "a conscientização do papel da cultura é necessária para construção, percepção e tradução da realidade" (p.1). Trata-se da reescrita de uma língua em uma cultura e contexto específicos para outra língua em outra cultura e contexto específicos (LEFEVERE, 2007). A reescrita que o ato pressupõe ganha sentido a partir da interatividade sociodiscursiva entre autor, texto e leitor.

Nesse sentido, o ato tradutório nos contextos de formação de professores de língua estrangeira deve ser visto como uma prática que cria ligações, que estabelece vínculos entre as pessoas, que gera interfaces. Para isso é preciso que a tradução da letra abarque as particularidades e o diálogo das individualidades criadoras do espírito. Com isso, o texto traduzido, a obra em movimento, abarcará as condições socioculturais em que foi produzido, e para o qual está sendo traduzido, o que pode evitar a ocorrência de traduções artificiais e sujeitas a desvios e enganos linguísticos.

Apesar de no atual cenário acadêmico ainda existir uma tendência para a tradução literal, tanto que os dicionários convencionais ou virtuais são os instrumentos mais utilizados pelos aprendizes, os Estudos de Tradução têm ganhado nova roupagem e a preocupação especial com os aspectos linguísticos vem sendo substituída por questões de ordem intercultural. Nesse sentido, é necessário o entendimento de que "a tradução não acontece no vácuo, mas em um contínuo; ela não é um ato isolado, mas parte de um processo de transferência intercultural" (BASSNETT, 1999, p. 21).

\section{Análise das estratégias utilizadas pelos estudantes para tradução-compreensão do poema Balada do Cárcere de Reading}

A análise foi realizada por meio da observação de uma atividade desenvolvida pelos alunos do terceiro ano do Curso de Letras na disciplina de Literatura Inglesa. Para tanto, foram observadas quatro aulas de cinquenta minutos ministradas no período de uma semana.

O poema eleito para ser traduzido pelos estudantes trata-se um fragmento da obra de Oscar Wilde, presente no livro De Profundis, escrito quando o autor foi preso e condenado sob a acusação de ferir a moral social por meio da prática de homossexualidade após o escandaloso caso em que se envolveu com Lord Alfred Douglas. 
De Profundis se constitui em uma longa carta, cujo conteúdo pode ser resumido em recriminações a seu ex-amante e causa de toda a "sua desgraça". Nesse documento Wilde explica sua conduta sem tentar defendê-la. Faz parte deste volume a célebre 'Balada do Cárcere de Reading', considerado seu melhor poema. O texto na íntegra relata o dia-a-dia na prisão sob a visão de Oscar Wilde, sendo que em alguns momentos o autor parece ser subitamente tomado pela dor do abandono e insere trechos que denotam recriminações a seu ex-amante.

A obra foi escolhida para este trabalho por se tratar de um texto formado por frases absolutas ou períodos compostos, em sua maioria, por orações coordenadas, o que facilitaria o trabalho tradutório a ser desenvolvido pelos estudantes.

Para apresentar o resultado da análise das estratégias utilizadas na tradução pelos estudantes, foram selecionadas algumas palavras e expressões do poema que evidenciaram os caminhos percorridos na tradução para realizar a compreensão do texto. Não foram apresentadas todas as palavras e expressões utilizadas pelos alunos, mas somente aquelas que denotaram estratégias de tradução relevantes para este estudo.

The ballad of Reading gaol

Oscar Wilde

He did not wear his scarlet coat,

for blood and wine are red,

and blood and wine were on his hands

when they found him with the dead,

the poor dead woman whom he loved,

and murdered in her bed.

I never saw a man who looked

with such a wistful eye

upon that little tent of blue

which prisoners call the sky,

and at every drifting cloud that went

with sails of silver by.

I walked, with other souls in pain, within another ring,

and was wondering if the man had done

a great or little thing,

when a voice behind me whispered low,

"that fellows got to swing".

I only knew what hunted thought

quickened his step, and why

he looked upon the garish day 
with such a wistful eye; man had killed the thing he loved and so he had to die.

Yet each man kills the thing he loves

by each let this be heard, some do it with a bitter look, some with a flattering word, the coward does it with a kiss, the brave man with a sword!

The Governor was strong upon the Regulations Act:

the Doctor said that Death was but a scientific fact:

and twice a day the Chaplain called and left a little tract.

We sewed the sacks, we broke the stones, we turned the dusty drill:

we banged the tins, and bawled the hymns, and sweated on the mill: but in the heart of every man terror was lying still.

The warders with their shoes of felt crept by each padlocked door, and peeped and saw, with eyes of awe, grey figures on the floor, and wondered why men knelt to pray who never prayed before.

The warders strutted up and down, and kept their herd of brutes, their uniforms were spick and span, and they wore their Sunday suits, but we knew the work they had been

by the quicklime on their boots.

And all the while the burning lime eats flesh and bone away, it eats the brittle bone by night, and the soft flesh by the day, it eats the flesh and bones by turns, 
but it eats the heart always.

\author{
In Reading gaol by Reading town \\ there is a pit of shame, \\ and in it lies a wretched man \\ eaten by teeth of flame, \\ in a burning winding-sheet he lies, \\ and his grave has got no name.
}

\title{
He did not wear his scarlet coat
}

(...)

$\mathrm{O}$ primeiro caso observado foi em relação à palavra reading no título: Balada do Cárcere de Reading. Num primeiro momento os estudantes arriscaram traduzir como o verbo "ler" no gerúndio, mas rapidamente descartaram a hipótese, considerando que a palavra era precedida de uma preposição. Logo, seria um substantivo e não um verbo no gerúndio, conhecimento mais simples que detinham de uma palavra terminada com ing. No entanto, esgotados os conhecimentos morfológicos, a tradução do título do poema ainda parecia incorrer em desvios e enganos linguísticos, o que instigou alguns estudantes a procurar o significado da palavra na internet, que é apresentada em letra maiúscula (capital letter) no poema. Com isso aludiram que se tratava do nome de uma cidade localizada no Reino Unido e também de uma grande Universidade localizada nessa cidade: Reading.

Nesse contexto os estudantes iniciaram suas inferências apoiando-se nos conhecimentos prévios sobre do léxico, passaram por conhecimentos morfossintáticos, porém ajustaram a tradução utilizando informações interculturais acerca do vocábulo disponíveis na web. Isso reflete o pensamento de Bassnet (1999) quando a autora defende que o ato de traduzir constitui-se, sobretudo no envolvimento profundo e comprometido com questões relativas à interação cultural, isso porque a tradução é um processo implantado em sistemas políticos e culturais, assim como na história. Nessa perspectiva, o tradutor deve também estar inserido no contexto das línguas com as quais está trabalhando, deixando de ter apenas responsabilidades em relação às línguas de trabalho, mas tornando-se um mediador de culturas. Nessa perspectiva, ao longo do processo de tradução surgem dúvidas "que podem ser sanadas baseadas em conhecimento prévio, linguístico e cultural e em informações que podem ser levantadas fora do texto, por meio de pesquisas em textos paralelos e outros" (PAGANO, 2014, p.19).

Para a palavra for, na segunda linha do poema: for blood and wine are red, os alunos percorreram basicamente o mesmo caminho utilizado para traduzir a palavra reading: do conhecimento prévio do léxico, para a classe gramatical (preposition), logo o vocábulo seria facilmente traduzido como a preposição "por", "para" ou outro vocábulo com carga semântica semelhante, não fosse o sentido da expressão que ficou comprometido na tradução da frase. Nesse momento os alunos recorrem ao tradutor online e descobrem outras sinonímias e classes gramaticais para a palavra "for". Nesse caso, ajustaram a tradução final elegendo a conjunção explicativa em português "porque", até então desconhecida como equivalente para a preposição "for". Percebe-se nessa estratégia que o que desfavoreceu a tradução da palavra foram questões de ordem semântica, o que foi deslindado com o uso do dicionário. 
Para Nida (1964 apud RODRIGUES, 2000, p. 68), em vez de proceder às transferências de uma língua para outra lidando com uma série de estruturas formais equivalentes,

É mais eficiente cientificamente e na prática: 1. reduzir o texto-fonte aos seus núcleos (kernels) estruturalmente mais simples e mais evidentes semanticamente. 2.Transferir o significado da língua-fonte para a língua receptora em um nível estruturalmente simples e mais evidente semanticamente. 3 transferir o significado da língua-fonte para a língua receptora em um nível estruturalmente simples. 3. Gerar a expressão estilística e semanticamente equivalente na língua receptora.

Nota-se com isso que os estudantes percorreram as estratégias sugeridas por Nida (1964), no entanto esbarraram no raso conhecimento semântico que detinham do vocábulo na língua inglesa, o que foi superado pelo uso do tradutor online. Entretanto, o que determinará o nível de autonomia dos estudantes no processo tradutório é ter o entendimento "dos caminhos que foram percorridos para transformar uma estrutura (x) na língua de partida em uma estrutura (y) na língua de chegada". (ALVES, 2014, p. 34).

A palavra blue no trecho: I never saw a man who looked, with such a wistful eye, upon that little tent of blue, which prisoners call the sky foi a terceira unidade lexical escolhida para explicar as estratégias e decisões de traduções utilizadas pelos estudantes. Toda a turma traduziu a palavra naturalmente como "azul". Todavia, na sequência foi observada incoerência no sentido da frase. De forma análoga ao item lexical analisado no parágrafo anterior, os estudantes recorreram a conhecimentos morfossintáticos e deduziram que nesse contexto específico o fato de blue estar acompanhado da preposição of não poderia ser traduzida como um adjetivo. Nesse caso o único conhecimento semântico e morfológico que os estudantes detinham da palavra blue era o adjetivo azul.

Para que os estudantes chegassem a um nível satisfatório da tradução foi feita com a orientação do professor, uma interpretação das estrofes utilizando os termos já conhecidos e, a partir daí, fizessem conjecturas sobre a carga semântica da que palavra blue carrega, sobretudo nos textos poéticos. As inferências foram confirmadas a partir da relação estabelecida com a palavra sky ( céu) no final do verso seguinte. Nesse caso os estudantes relacionaram a palavra "azul" com "céu" para negociar a tradução, mas não apreenderam logo no início que a tradução de blue para "azul" poderia ser feita de forma simples sem incorrer em desvios linguísticos, considerando que "azul" também pode assumir a função de substantivo, como no exemplo: "o azul é o meu".

Nesse sentido, vale retomar Alves (2014) quando que advoga que "muitas vezes nos deparamos com itens lexicais desconhecidos, estruturas sintáticas incompreensíveis, ambiguidades semânticas de difícil solução" (p.29) e com Jakobson (2008), que diz que "buscar a equivalência na diferença é a principal preocupação linguística" (p. 65).

Para chegar a uma compressão da expressão utilizada os estudantes partiram do conhecimento lexical que foi refutado, quando confrontado com questões morfossintáticas, demonstrando que a literalidade, ou tradução palavra por palavra normalmente não colabora para a criação de um texto.

O quarto item lexical analisado foi sewed no verso: We sewed the sacks, we broke the stones. Para esse item os alunos utilizaram mecanismos inferenciais, considerando o conhecimento que detinham de equivalentes em português para a maioria das palavras do verso. Apenas a palavra sewed gerou problemas de tradução, pois ao consultar o dicionário bilíngue inglês/português, foi encontrado o equivalente "coser". Apesar do entendimento por 
parte da turma de que as referências utilizadas no texto de partida são essenciais para uma tradução adequada , nesse caso específico, esse item lexical causou "transtornos" nas decisões de tradução tomadas pelos estudantes.

Considerando o pronome sujeito we, finalmente traduziram como cosíamos, no entanto a mensagem no texto de chegada permaneceu estranha, mas dessa vez porque nenhum dos alunos da turma compreendeu coser como costurar e sim como cozinhar, demonstrando conhecimento semântico fragilizado de vocábulos também na língua materna no processo de tradução.

De acordo com Pagano ( 2014, p. 41),

Quando bom, o dicionário bilíngue é apenas um dos recursos existentes, cuja utilização requer a verificação ou checagem das informações em outros tipos de dicionários, como é o caso dos dicionários monolíngues, que oferecem uma descrição ou explicação do termo procurado.

Para Goethe, quem não conhece línguas estrangeiras não sabe nada da sua própria, afirmação utilizada de forma inversa por Oustinoff (2011, p. 10): "um conhecimento que cada um tenha da própria língua, contém em potencial, o conhecimento de todas as outras por intermédio da tradução".

O último item eleito para análise foi "quicklime" nos versos: ... but we knew the work they had been by the quicklime on their boots. Os estudantes utilizaram mecanismos inferenciais, conhecimentos morfossintáticos e lexicais no texto de chegada de forma satisfatória, no entanto não chegaram a um entendimento adequado do verso, por não conseguirem estabelecer nenhum tipo de relação da "cal" (quicklime) com o trabalho que os guardas tinham feito. No poema, esse "trabalho" se refere à execução de presos pelos guardas dentro do presídio, com isso a presença da "cal" deixou dúvidas acerca das decisões de tradução tomadas para o verso.

Diante disso, foram orientandos a buscar subsídios na internet e descobriram que a "cal", dentre outras funções, também é utilizada para neutralizar odores, logo, no poema as "botas sujas de cal" pode denotar que os guardas fizeram " o trabalho" completo, não deixando sinais de odores.

A busca de subsídios externos, como a consulta a textos paralelos, o uso do dicionário, da internet como grande banco de informações e a utilização de recursos computadorizados são algumas das ações que os estudantes podem efetuar quando se depara com um problema de tradução para o qual não se encontra resolução rápida e acertada (PAGANO, 2014, p.55).

Observou-se nessa última estratégia que os estudantes analisaram de perto os itens lexicais, identificando as condições lexical e sintática para, posteriormente, conferir um sentido global para o verso.

\section{Considerações finais}

A atividade de observação das estratégias de tradução interlingual utilizadas pelos estudantes revelou que esses, normalmente percorrem caminhos similares para chegar a uma compreensão adequada do texto na língua de chegada. Classificamos as estratégias adotadas na atividade como: conhecimentos macrotextuais, mecanismos inferenciais, conhecimentos interculturais, consulta ao dicionário, informações contextuais.

Normalmente, os estudantes partem de conhecimentos macrotextuais que se referem ao conhecimento prévio de mundo. Este conhecimento de mundo envolve toda bagagem cultural e informação procedimental que instrui como melhor utilizar aquilo que já se 
conhece e assim, poder processar cada parte do texto construindo conjecturas acerca do seu possível desenvolvimento subsequente.

Ficou evidenciado que utilizam mecanismos inferenciais os quais podem ser tratados como pré-texto, o ponto em que estamos, com todas as informações que já dispomos para processar informações novas que já recebemos. As inferências feitas pelos alunos revelaram conhecimentos relacionados a aspectos léxico-semânticos e especialmente morfossintáticos.

Outra estratégia recorrente foi a utilização de conhecimentos interculturais. Essa estratégia constituiu a última ação desenvolvida pelos estudantes, que a utilizavam quando esgotada a estratégia de conhecimento macrotextual e os mecanismos inferenciais. Para chegar a conhecimentos relacionados à cultura do texto da língua de chegada os estudantes faziam uso de subsídios externos, especialmente computador e internet.

A consulta ao dicionário bilíngue especialmente na forma impressa se revelou bastante tímida, uma vez que preferiram utilizar o tradutor online. Entretanto, quando o dicionário online não contribuía para decisões de tradução, optavam pelo impresso, especialmente o inglês/inglês, que apresenta diferentes acepções para um mesmo vocábulo, além de exemplos contextualizados de uso.

As informações contextuais foram as mais utilizadas como estratégias de tradução, considerando que essas forneciam pistas para que os estudantes tomassem decisões de tradução de vocábulos de expressões que não faziam sentido quando traduzidos utilizando formas convencionais.

É válido explicitar que de nenhuma maneira foi nossa pretensão, durante a realização desse estudo, investigar os defeitos ou as qualidades das estratégias, tampouco estabelecer relação de hierarquia entre uma e outra, mas, sim, de apresentar as particularidades que as estratégias revelam. Esperamos que as reflexões aqui explicitadas possam colaborar para o desenvolvimento de bases sólidas que culminem em novas práticas envolvendo professores de língua inglesa em formação no que tange ao trabalho com tradução interlingual em sala de aula. 


\section{Referências}

ALVES, Fábio. Estratégia de busca de internos: memória e mecanismos inferenciais. . In: PAGANO, Adriana, MAGALHÃES, Célia, ALVES, Fábio. (org). Traduzir com autonomia: estratégias para o tradutor em formação. 4.ed- São Paulo: Contexto: 2014.

BAKHTIN, M. Estética da criação verbal. Trad. Paulo Bezerra. São Paulo: Martins Fontes, 2003.

BASSNETT, S.; TRIVEDI, H. (eds.). Post-colonial Translation: theory and practice. London: Routledge, 1999. BELL, R. Translation

BEZERRA, Paulo. A tradução como criação. Disponível em http://www.scielo.br/scielo.php?pid=S010340142012000300007\&script=sci arttext. Acesso em 25 de janeiro/ 2015.

GOROVITZ, Sabine, A tradução enquanto situação de passagem. In.: BELL, Santos, CYNTHIA Ann, ROSCOE-BESSA, Cristiane, HATJE-FAGGION, Válmi (org).Tradução e Cultura, Rio de Janeiro: 7 Letras, 2011.

JAKOBSON, Roman. Linguística e comunicação. São Paulo: Cultrix, 2008.

KATAN, David. Translating cultures: an introduction for translators, interpreters, and mediator. 2 nd ed. Manchster, UK: St. Jorome Publishing , 2004.

LEVEFERE, Andre. Tradução, reescrita e manipulação da fama literária. Bauru: Edusc, 2007

Nida, Eugene A. Toward a science of translating. Leiden: E. J. Brill.1964. In RODRIGUES, Cristina Carneiro. Tradução e diferença. São Pulo: Editora UNESP, 2000.

OUSTINOFF, Michael. Tradução: Histórias, teorias e métodos. Tradução: Marcos Marcionilo, São Paulo: Parábola Editorial, 2011.

PAGANO, Adriana. Estratégia de busca de externos: fontes textuais e recursos computacionais. In: PAGANO, Adriana, MAGALHÃES, Célia, ALVES, Fábio. (org). Traduzir com autonomia: estratégias para o tradutor em formação. 4.edSão Paulo: Contexto: 2014. 